\title{
THE INCIDENCE AND SIGNIFICANCE OF IRON- CONTAINING GRANULES IN HUMAN ERYTHROCYTES AND THEIR PRECURSORS
}

\author{
BY \\ A. S. DOUGLAS AND J. V. DACIE \\ From the Department of Pathology, the Postgraduate Medical School of London
}

(RECEIVED FOR PUBLICATION AUGUST 28, 1953)

The iron in haemoglobin cannot normally be detected in the erythrocytes of healthy human adults by means of a staining technique. However, Grüneberg (1941a and b) used the term " siderocyte" to describe erythrocytes containing small granules readily demonstrable by means of Perls's (Prussian blue) reaction. He found these cells in small numbers in the blood of normal rat, mouse, and human embryos (Grüneberg, 1941a and b), and later (Grüneberg, 1942) in large numbers in the blood of mice suffering from congenital anaemia. Doniach, Grüneberg, and Pearson (1943) described the occurrence of siderocytes in adult human blood. They found $15 \%$ of siderocytes in a patient with hepatic cirrhosis who had undergone splenectomy, and small numbers ( $1 \%$ or less) in four patients whose spleens had been removed for splenic anaemia, thrombocytopenic purpura, or traumatic rupture. Pappenheimer, Thompson, Parker, and Smith (1945) described the appearance of erythrocyte inclusion bodies in three patients whose anaemia persisted after splenectomy. In two patients the anaemia was haemolytic in type; in the third it was of undetermined type. They found that the inclusions in the erythrocytes stained with Romanowsky dyes as well as giving a positive Perls's reaction ; the Feulgen reaction was, however, negative. McFadzean and Davis (1947) extended the observations of Pappenheimer et al. (1945), and referred to the inclusions demonstrable by Romanowsky dyes as "Pappenheimer bodies." Grüneberg (1942), McFadzean and Davis (1947), and Dacie and Doniach (1947) observed that inclusion bodies identical in staining reaction with those seen in the peripheral blood were present in marrow normoblasts in which there was evidence of haemoglobin formation. Dacie and Doniach (1947) independently confirmed that the basophilic granules described by Pappenheimer et al. (1945) contained iron in an ionized form. McFadzean and Davis (1949) re-investigated the nature of stippling in lead poisoning. They found that many of the normoblasts in the bone marrow had large basophilic granules in their cytoplasm, i.e., were stippled, and that a variable proportion of the granules gave a positive reaction for iron. Splenectomy of lead-poisoned guinea-pigs resulted in a very considerable increase in the frequency of stippled cells in the peripheral blood.

More recently Bilger and Tetzner (1953) have reported the presence of siderocytes in small numbers in the peripheral blood of some healthy subjects, in newborn infants, and in various haemolytic anaemias. They obtained higher counts in blood from the bone marrow, and in peripheral blood after splenectomy. Other recent reports in which high siderocyte counts have been observed in patients submitted to splenectomy include those of Mills and Lucia (1949), Estren and Dameshek (1949), Mills, Huff, Krupp, and Garcia (1950), and Crosby (1950). Valtis (1951) reported the occurrence of numerous siderocytes in patients with Mediterranean anaemia following splenectomy.

Siderocytes are thus well recognized, but their exact incidence and pathogenesis remain obscure. In particular, it is not clear how abnormal the phenomenon is, and what exactly is the role of the spleen. Case (1946), using the $\alpha \alpha^{\prime}$ dipyridyl technique, considered that siderocytes were ageing corpuscles, but the finding of siderotic granules in developing normoblasts is entirely against this hypothesis, and most authors have considered that the granules develop as the result of an abnormality in haemoglobin metabolism (Doniach, et al., 1943; McFadzean and Davis, 1947, 1949 ; Bilger and Tetzner, 1953). McFadzean and Davis $(1947,1949)$ suggested that the rise in numbers in the peripheral blood after splenectomy was the result of the spleen previously filtering off erythrocytes containing Pappenheimer bodies from the circulation. Bilger and Tetzner (1953), on the 
other hand, assigned two roles to the normal spleen ; the prevention of siderocyte formation as well as the removal of siderocytes from the peripheral blood. Our own studies have been undertaken in an attempt to clarify the problem. They have led to the conclusion that siderotic granule formation occurs normally in ripening normoblasts except where there is iron deficiency. The phenomenon, however, is normally a transient one, and in health the granules disappear at the reticulocyte stage at the latest. Splenectomy possibly exerts its effect mainly by a slowing down of the rate at which the siderotic granules become metabolized.

\section{Material and Methods}

The material investigated was drawn from the patients investigated in this laboratory during the last six years. The normal marrows were obtained from healthy volunteers. Films of peripheral blood and marrow were prepared ańd stained by the May-Grünwald-Giemsa method, as described by Dacie (1950). Some of the material was stained for iron at the time of collection : other slides originally stained by MayGrünwald-Giemsa were decolorized for 12 hours in methyl alcohol before staining for iron. For demonstration of iron the films were fixed in methyl alcohol for 10 to 20 minutes, then treated for 10 minutes with a freshly prepared mixture of equal parts of a $2 \%$ solution of potassium ferrocyanide (Analar) and 2\% hydrochloric acid in distilled water. It was found that temperature was critical in this reaction, for at room temperature only a proportion of the iron-containing granules stained. More consistent results were obtained by carrying out the staining in a $56^{\circ}$ waterbath. The mixture of potassium ferrocyanide and hydrochloric acid was first warmed at $56^{\circ}$ for a minute or so and then poured into a jar containing the slides to be stained. Heating above $56^{\circ}$ or staining for longer than 10 minutes tended to precipitate the stain. The slides were then washed in running tap water for 20 minutes, rinsed in buffered distilled water ( $p H$ 6.8), and counter-stained with $0.1 \%$ safranin. Safranin rather than eosin was used, for the former stains nuclear detail; the dilute solution was prepared immediately before use from a stock $0.5 \%$ aqueous solution. A microscope with optimal powers of resolution is important in the identification of the iron granules.

Successive staining of reticulocytes and siderocytes in peripheral blood and marrow was carried out as follows: Films of cresyl blue were made on slides using a $1 \%$ alcoholic solution. A drop of blood or marrow was placed on the slide, mixed with the cresyl blue with the corner of a slide, and then spread. This film was subsequently fixed in methyl alcohol, stained for iron, and then counterstained with safranin. The safranin stains the reticulo-filamentous material red, and the granules appear blue against a pale-red background. Heavy counterstaining is to be avoided.
The presence of stainable iron in the marrow (excluding that in erythroblasts) was assessed by examination of marrow fragments left intact on the slide as well as by the examination of histological sections. The former method was found to be as satisfactory as the latter.

\section{Results}

Morphology of Siderocytes.-Siderocytes vary from cells or normal shape, size, and haemoglobin content containing granules just within the range of visibility, to cells grossly deficient in haemoglobin containing large granules up to $2 \mu$ in diameter. The commonest type of siderocyte contains a single or double granule usually situated towards the periphery of the cell. The granules vary in number from one to 12 or more (Fig. 1, f to $\mathrm{j}$ ); a large number is rare, and when as

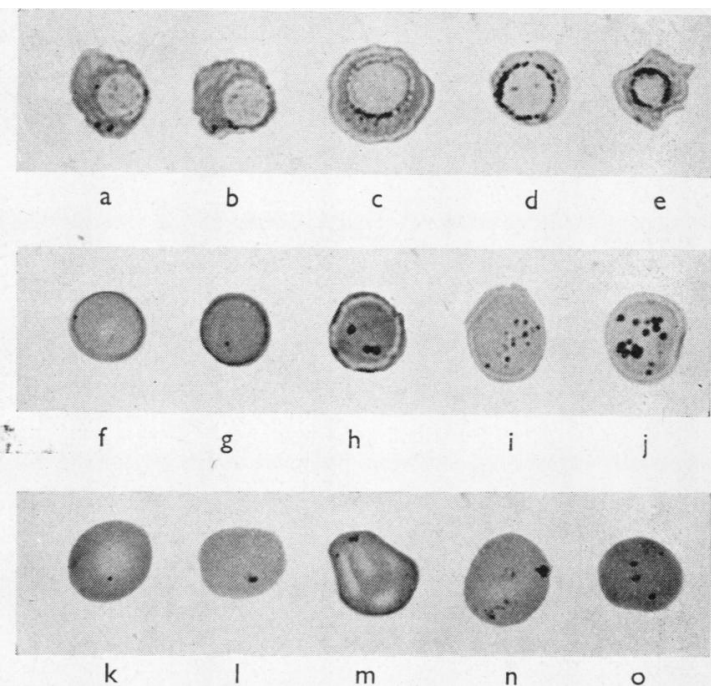

FIG. 1.-Phc tomicrographs of normoblasts and erythrocytes stained (b) by Jenner-Giemsa to show "Pappenheimer bodies" $(\mathrm{k}-\mathrm{j})$,

numerous as 10 to 12 they are usually but not always small. As a rule the larger the granules the less numerous they are. When very large granules are present the haemoglobin is represented by a thin layer round the periphery of the cell leaving a large central almost unstained area ; in this rim of haemoglobin is set the ironcontaining granule (Fig. $\cdot 2)$. When there is more than one granule they are usually situated close together and are often contiguous. In any one patient the siderocytes tend to be more or less of the same type.

When siderocytes are present in the peripheral blood equivalent numbers of cells containing Pappenheimer bodies will be found. The mean 


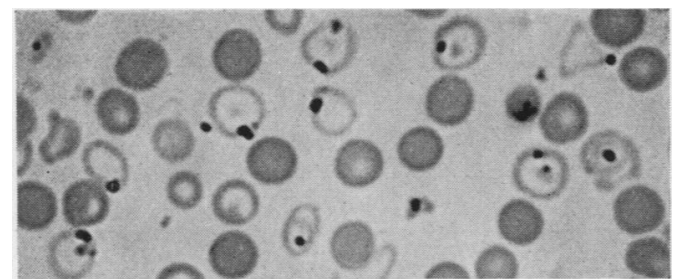

Fig. 2.-Photomicrograph of the peripheral blood film of a patient with a congenital defect in haemoglobin metabolism after splenectomy. The patient had been transfused, and the normal erythrocytes contrast markedly with the hypochromic erythrocytes of the patient (Jenner-Giemsa stain).

results of 21 comparative observations were almost identical, $22.6 \%$ of siderocytes compared with $22.9 \%$ of cells containing Pappenheimer bodies. However, individual observations did not always agree so well, there being variations in both directions. In some cases this may have been due to inadequate staining; it seems probable though that granules do really vary in their relative contents of iron and basophilic component, and that some granules may be stained by one method but not by the other.

If cells showing diffuse punctate basophilia are studied it is found that only a few, if any, of the granules are iron-containing (Dacie and Doniach, 1947). This is well seen in ferrocyanidestained films counterstained with safranin which stains the iron-negative granules red.

Morphology of Iron-staining Granules in Erythroblasts. - In the marrow in health and in a wide range of blood disorders the erythroblasts often contain iron granules. This is also true of erythroblasts occurring in the peripheral blood. The iron-containing granules vary in number from one to $\mathbf{1 0}$ or more. In size they vary from those just visible to the eye to very large granules $2-3 \mu$ in diameter found only in pathological states. They are usually present in erythroblasts showing evidence of haemoglobin formation; in certain pathological marrows they were present in very early basophilic normoblasts. Sometimes the granules form a ring round the nucleus (Fig. 1, a to e).

In marrow preparations stained with Romanowsky dyes these iron-containing granules are generally not visible. Usually the cytoplasm of the erythroblasts containing the granules shows diffuse uniform polychromasia only. Exceptionally in pathological states in erythroblasts that show coarse basophilic punctation some of the granules give a positive reaction for iron.

Incidence of Iron-containing Granules.-In Table $I$ is set out the incidence of siderocytes and erythroblasts with iron-containing granules in the peripheral blood and bone marrow of normal persons and of patients suffering from a wide range of blood disorders.

In Normoblasts and Megaloblasts.-It was of interest to find that iron-containing granules were present in a large proportion of the normoblasts of all the normal marrows examined. Similarly, of all the pathological marrows it was only in those from patients with iron-deficiency anaemia that the normoblasts were consistently free from iron-positive granules. When iron-deficient patients were treated with iron the granules returned to the marrow normoblasts; in certain cases of polycythaemia vera where they were also absent a relative iron deficiency was likely.

The incidence of normoblasts with iron-positive granules in normal marrows ranged from $24 \%$ to $81 \%$, with a mean value of $49 \%$. In other conditions the incidence of granule-containing normoblasts was generally within this range. In pernicious anaemia the proportion of erythroblasts containing iron-positive granules markedly decreased as compared with the proportion of megaloblasts containing iron when the marrow returned to normoblastic erythropoiesis in response to therapy. This is interpreted as the consequence of a relative deficiency of available iron in the marrow at the time of its maximum activity.

In a group of three cases shown near the end of Table I there was a probable defect of haemoglobin synthesis. In one case the defect was congenital: the other two patients were adults with an acquired but similar morphological defect. In these cases the granules in the normoblasts were particularly large.

The presence or absence of stainable extracorpuscular haemosiderin in the marrow was correlated with the incidence of iron-positive granules in erythroblasts. In the cases of iron deficiency with absence of iron-positive granules in the normoblasts extracorpuscular haemosiderin could not be demonstrated in the marrow. However, absence of iron from the marrow was not necessarily accompanied by absence of iron granules in the normoblasts. It seems that iron granules only disappear from the normoblasts in the more severe grades of iron deficiency. On the other hand, in all marrows in which extracorpuscular iron was demonstrable the normoblasts also contained iron. Where the marrow iron was greatly increased, as for instance by repeated transfusion, this did not as a rule result in an obvious increase in the size of the iron granules in erythroblasts. An added factor of 
failure in haemoglobin formation seemed to be necessary for the development of particularly large granules.
In the Peripheral Blood Erythrocytes.-Siderocytes were not found in the blood of the normal 을 adults we examined, and it seems clear that if

TABLE I

INCIDENCE OF IRON-CONTAINING GRANULES IN ERYTHROCYTES AND THEIR PRECURSORS IN PERIPHERAL BLOOD AND BONE MARROW IN HEALTH AND BLOOD DISORDERS

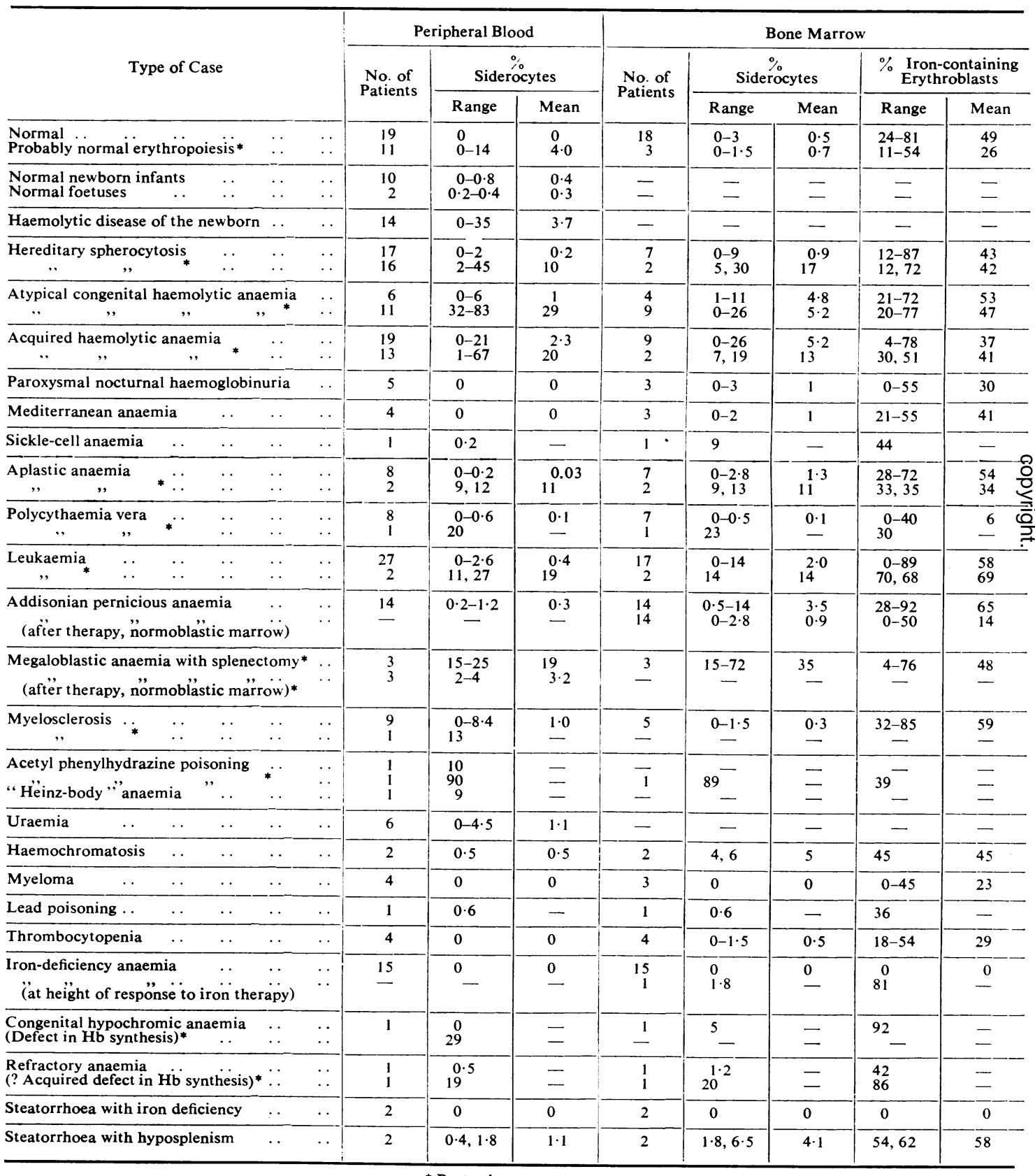




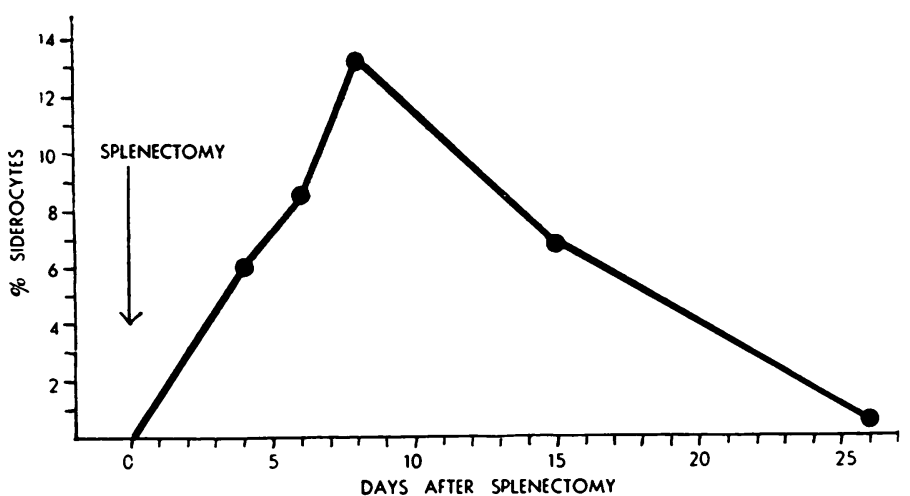

FIG. 3.-Transient appearance of large numbers of siderocytes in the peripheral blood of a boy splenectomized for hereditary spherocytosis.

in the course of the gastrectomy. In the haemolytic anaemias siderocytes were most numerous in cases of the atypical congenital type (Dacie, Mollison, Richardson, Selwyn, and Shapiro 1953) ; they were almost as frequent in certain cases of acquired haemolytic anaemia with auto-antibodies. They were present in much smaller numbers in hereditary spherocytosis, the granules being generally very small; in one out of 16 patients none was found (after splenectomy).

In Fig. 3 is illustrated the transient occurrence following splenectomy of large numbers of siderocytes in the

present at all in health the numbers circulating must be extremely small. In disease it was unusual to find them in any great numbers in the peripheral blood in any condition in the absence of splenectomy. Notable exceptions to this were isolated cases of haemolytic disease of the newborn, atypical congenital haemolytic anaemia, acquired haemolytic anaemia, phenylhydrazine poisoning, uraemia, and myelosclerosis. Smaller numbers were found in a variety of blood disorders (Table I).

Splenectomy was associated with a considerable number of siderocytes in the peripheral blood irrespective of the nature of the primary condition.

An approximately equivalent number of Pappenheimer bodies was also present. The disorders from which the patients (without spleens) were suffering included, in addition to haemolytic anaemia, polycythaemia vera, leukaemia, megaloblastic anaemia following gastric operations, myelosclerosis, phen y l h y drazine poisoning, and aplastic anaemia. In the patients with megaloblastic anaemia following gastric operations, the spleen had been removed for technical reasons peripheral blood of a patient with hereditary spherocytosis. This was an unusual and unexplained finding. In Fig. 4 is shown the rise in the peripheral-blood siderocyte count after splenectomy in a patient with atypical congenital haemolytic anaemia. The siderocytes began to appear the day after the operation, but did not reach their maximum number until some weeks later.

It is evident that siderocytes may be present in large numbers in patients submitted to splenectomy for conditions other than haemolytic anaemia. But they are not always found. In three of 11 patients (not suffering from haemolytic anaemias)

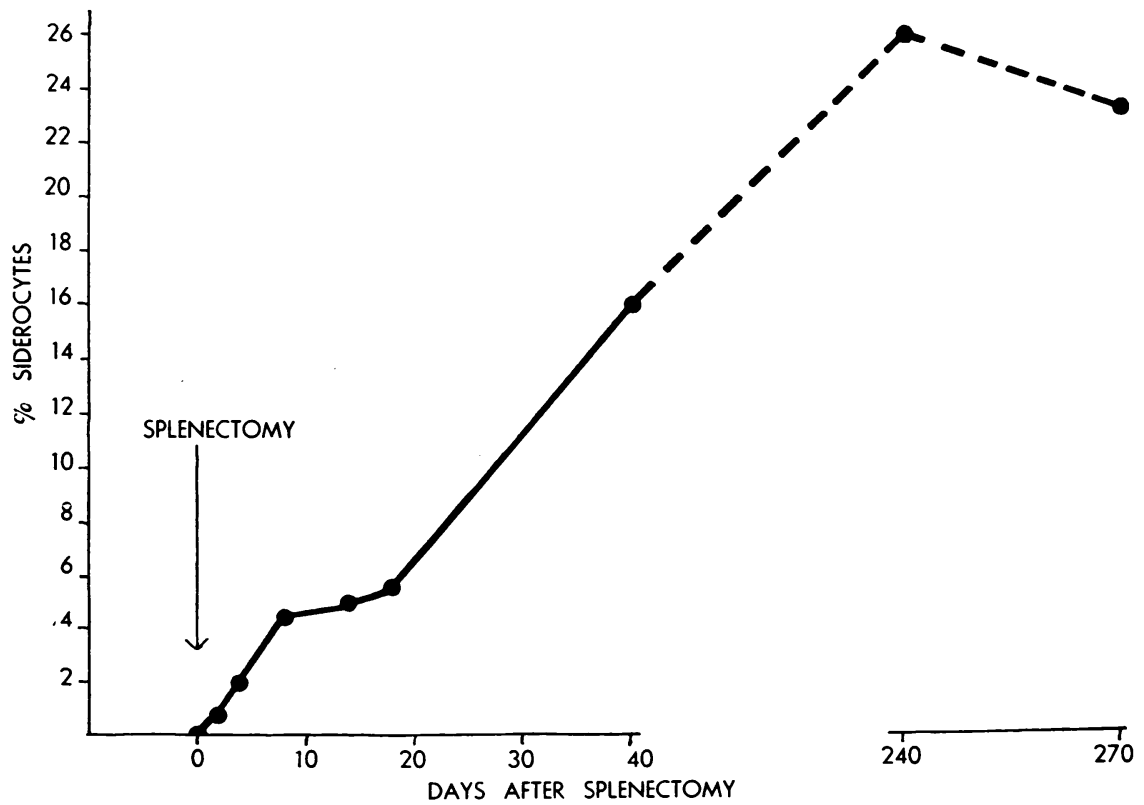

FIG. 4.-Progressive development of siderocytes in the peripheral blood of a boy splenectomized for an atypical congenital haemolytic anaemia. 
erythropoiesis was probably normal none could be found. In the other patients of this group the granules were usually small. The granules were largest after splenectomy in patients apparently suffering from congenital or acquired defects of haemoglobin metabolism. In patients with megaloblastic anaemias following gastrectomy (and splenectomy) the incidence of siderocytes in the peripheral blood decreased when their anaemia was treated with vitamin $B_{12}$ or folic acid.

TABLE II

INCIDENCE OF IRON-CONTAINING GRANULES IN RETICULOCYTES AND MATURE ERYTHROCYTES COMPARED

\begin{tabular}{c|c|c|c|c}
\hline & $\begin{array}{c}\% \\
\text { Iron-negative } \\
\text { Reticulocytes }\end{array}$ & $\begin{array}{c}\text { Iron-positive } \\
\text { Reticulocytes }\end{array}$ & $\begin{array}{c}\% \\
\text { Iron-negative } \\
\text { Mature } \\
\text { Erythrocytes }\end{array}$ & $\begin{array}{c}\text { Iron-positive } \\
\text { Mature } \\
\text { Erythrocytes }\end{array}$ \\
\hline $\begin{array}{c}\text { Mean of six } \\
\text { observa- } \\
\text { tions ... }\end{array}$ & 10.7 & 8.9 & $73 \cdot 1$ & 7.3 \\
\hline
\end{tabular}

TABLE III

INCIDENCE OF IRON-CONTAINING GRANULES IN MARROW NORMOBLASTS, MARROW RETICULOCYTES, AND MATURE MARROW ERYTHROCYTES COMPARED

\begin{tabular}{c|c|c|c}
\hline & $\begin{array}{c}\% \\
\text { Iron-positive } \\
\text { Normoblasts' }\end{array}$ & $\begin{array}{c}\% \\
\text { Iron-positive } \\
\text { Reticulocytes }\end{array}$ & $\begin{array}{c}\% \\
\text { Iron-positive } \\
\text { Mature } \\
\text { Erythrocytes }\end{array}$ \\
\hline $\begin{array}{c}\text { Mean of 11 obser- } \\
\text { vations }\end{array}$ & 30 & 31 & $2 \cdot 2$ \\
\hline
\end{tabular}

In marrow blood the incidence of siderocytes was consistently higher than in peripheral blood. In a series of studies on peripheral blood and bone marrow involving the simultaneous staining of iron and reticulo-filamentous material the incidence of iron-containing granules in the reticulocytes was found to be higher than in the non-reticulated cells (Tables II and III). It was also found that in the marrows of persons with few or no siderocytes in the peripheral blood, the siderocytes in the marrow were reticulocytes.

TABLE IV

INCIDENCE OF IRON-CONTAINING GRANULES IN MARROW NORMOBLASTS, IN PERIPHERAL BLOOD BEFORE SPLENECTOMY, IN SPLEEN BLOOD, AND IN PERIPHERAL BLOOD AFTER SPLENECTOMY COMPARED

\begin{tabular}{c|c|c|c|c}
\hline & $\begin{array}{c}\text { Normoblasts } \\
\text { in Bone } \\
\text { Marrow with } \\
\text { Iron-contain- } \\
\text { ing Granules }\end{array}$ & $\begin{array}{c}\text { Peripheral } \\
\text { Blood } \\
\text { Before } \\
\text { Splenectomy }\end{array}$ & $\begin{array}{c}\text { Spleen } \\
\text { Blood }\end{array}$ & $\begin{array}{c}\text { Peripheral } \\
\text { Blood } \\
\text { After } \\
\text { Splenectomy }\end{array}$ \\
\hline $\begin{array}{c}\text { Mean of 10 } \\
\text { observations }\end{array}$ & 53.8 & 2.4 & $2.0^{*}$ & $15+$ \\
\hline
\end{tabular}

- Spleen blood obtained by splenic puncture in three patients and at splenectomy in seven patients.

+ Mean of 7 patients only.
In 10 cases simultaneous comparisons of the siderocyte counts of peripheral blood, spleen 을 blood, and sternal marrow were made. In each $\vec{\Rightarrow}$ case there was a high incidence of iron-containing $\stackrel{0}{\rightarrow}$ granules in the marrow normoblasts but only $\bar{c}$ small numbers in spleen blood or peripheral blood $\frac{\overline{\bar{N}}}{\bar{T}}$ (Table IV). Seven of these patients produced $\frac{\text { क }}{\sigma}$ much higher numbers of siderocytes in the peri- $\stackrel{\mathbb{Q}}{\Omega}$ pheral blood after splenectomy. The other three \& patients did not undergo splenectomy.

\section{Discussion}

The observation of special significance in this 응 investigation is the finding of iron-containing granules in the normoblasts of normal marrows. $\rightarrow$ As a rule these iron-containing granules are not discernible in Romanowsky-stained films. It seems reasonable to presume that the iron in the normo- $\stackrel{\circ}{5}$ blasts is the precursor of the iron of siderocytes, $\vec{z}$ and that in association with basophilic staining $z$ material it forms the Pappenheimer body. The higher count of siderocytes amongst marrow $\bar{z}$ erythrocytes compared with peripheral blood $\stackrel{\mathbb{D}}{-}$ erythrocytes is correlated with the higher incidence $\vec{O}$ of reticulocytes in the marrow blood and the of higher incidence of iron-containing granules reticulocytes than in ripened non-reticulateg. erythrocytes. This suggests that siderocytosis is sign of cell immaturity and that the complete or $\overline{0}$ almost compete absence of siderocytes in the peri-

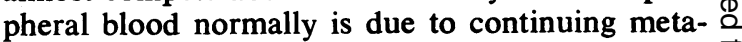
bolism within the cell resulting in the gradual $\overrightarrow{\overrightarrow{0}}$ disappearance of the iron as the cell matures. 3 Normally this process seems to be almost completed by the time the cell has reached the reticulocyte stage. It is significant perhaps that Walsh, Thomas, Chow, Fluharty, and Finch (1949) in studies with radioactive iron found that reticulo- 3 cytes but not adult erythrocytes were able to assimilate iron and synthesize haem in vitro and $\frac{3}{3}$ that this uptake of radio-iron could be used as an indication of the rate of haemoglobin synthesis. There was no exchange of iron between the $\frac{D}{0}$ mature erythrocytes and surrounding plasma.

The alternative hypothesis that siderocytes (or o the siderotic granules) are normally removed from $\mathrm{N}$ the circulation by the spleen appears to be less $\mathcal{N}$ likely. For example, more than $50 \%$ of the $\omega$ normoblasts in a normal marrow may contain siderotic granules at one stage; it appears $\stackrel{\bullet}{\llcorner}$ improbable that all the erythrocytes arising from $\varnothing$ these cells end their life in the spleen within so short a time of leaving the marrow that none can $\frac{0}{0}$ be detected in the peripheral blood. The alter- $\overrightarrow{\mathbb{D}}$ native hypothesis that the loss of iron-containing $\frac{\stackrel{\rho}{\mathbb{D}}}{\mathrm{O}}$ 
granules from normoblasts and erythrocytes is a maturation phenomenon akin to loss of the basophilic substance of reticulocytes appears to us to be more plausible. Moreover, where we have had the opportunity of examining spleen smears, we have failed to find the siderocytes which would be expected to be present in relatively large numbers if the spleen was in fact filtering them off from the circulation (Table IV). It certainly is possible where the siderocyte is a grossly abnormal cell with little haemoglobin and large iron-containing granules that such cells may be destroyed by the spleen (McFadzean and Davis, 1947, 1949 ; Pirrie, 1952). We feel, however, that this is unlikely to be the normal mechanism.

It appears probable, therefore, that siderotic granules in normoblasts normally represent iron not immediately incorporated into haem (Dacie and White, 1949). In iron deficiency the granules are not to be found. At the other end of the scale in cases where there is evidence of impaired haemoglobin formation not due to iron deficiency, as in Grüneberg's (1942) mice with a congenital anaemia, and as in rare human cases with possibly comparable defects, the iron-containing granules are exceptionally conspicuous.

Even if it seems improbable that the spleen normally removes siderocytes from the circulation, it nevertheless clearly influences the numbers that circulate in some way. Possibly it affects by some humoral mechanism the rate at which the iron is metabolized in the siderocyte ; if in the absence of the spleen the siderocytes were to mature more slowly, then there would be time for them to appear in the peripheral blood in relatively large numbers. It may be significant that in this series the largest numbers of siderocytes were found in some cases of haemolytic anaemia where following splenectomy there was a persistent reticulocytosis with many immature cells in the circulation. Possibly this hypothetical delayed ripening of siderocytes is analogous to the persistence of nuclear material after splenectomy as shown by the presence of Howell-Jolly bodies.

\section{Summary}

The incidence of iron-containing granules in erythrocytes and in their precursors has been studied in health and in blood diseases.

Iron-containing granules are present in health in many normal normoblasts ; they are found also in disease except where there is iron deficiency. The granules in erythroblasts are not normally visible when preparations are stained with Romanowsky dyes, but may become so if the iron is associated with deeply basophilic material.

Erythrocytes with iron-containing granules (siderocytes) are not normally found in significant numbers in the peripheral blood in health, but they may be seen in marrow blood. They are also generally but not invariably absent from the peripheral blood in disease. A higher proportion of siderocytes is found amongst reticulocytes than amongst adult erythrocytes. After splenectomy, for whatever reason, siderocytes are usually present in the peripheral blood in considerable numbers. The greatest numbers are found in cases of haemolytic anaemia with high reticulocyte counts persisting after splenectomy. The iron-containing granules of siderocytes appear as basophilic granules, "Pappenheimer bodies," when blood films are stained by Romanowsky dyes.

The development of iron-containing granules seems to be a transient phenomenon occurring during the formation of haemoglobin. Normally, the iron appears to be metabolized before the erythrocyte is completely ripened. After splenectomy it is probable that this ripening process is delayed.

One of us (A. S. D.) thanks the Medical Research Council for a fellowship in clinical research enabling him to take part in this work.

The majority of the patients investigated have been under the care of the medical staff of the Postgraduate Medical School of London, whom we should like to thank for their co-operation. We should also like to thank the many other physicians and pathologists who have allowed us to study their patients.

We should also like to thank Mr. E. V. Willmott, F.R.P.S., for the photomicrographs.

\section{REFERENCES}

Bilger, R., and Tetzner, K. H. (1953). Acta haemat., Basel, 9, 137. Case, R. A. M. (1946). Proc. roy. Soc., B, 133, 235

Crosby, W. H. (1950). Blood, 5, 233.

Dacie, J. V. (1950). Practical Haematology. Churchill, London. - and Doniach, I. (1947). J. Path. Bact., 59, 684.

Mollison, P. L., Richardson, N., Selwyn, J. G., and Shapiro, L. (1953). Quart. J. Med., 22, 79.

- and White, J. C. (1949). Journal of Clinical Pathology, 2, 1.

Doniach, I., Grüneberg, H., and Pearson, J. E. G. (1943). J.'Path. Bact. 55, 23.

Estren, S., and Dameshek, W. (1949). Advanc. intern. Med., 3, 45. Grüneberg, H. (1941a). Nature, Lond., 148, 114. (1941b). Ibid., 148, 469.

(1942). J. Genet., 44, 246.

McFadzean, A. J. S., and Davis, L. J. (1947). Glasgow med. J., 28, 237.

Mills, (1949). Quart. J. Med., 18, 57.

Mills, H., Huff, R. L., Krupp, M. A., and Garcia, J. F. (1950). Arch. intern. Med., 86, 711

- and Lucia, S. P. (1949). Blood, 4, 891.

Pappenheimer, A. M., Thompson, W. P., Parker, D. D., and Smith, K. E. (1945). Quart. J. Med., 14, 75.

Pirrie, R. (1952). J. Path. Bact., 64, 211.

Va:tis, D. J. (1951). University of Salonika, Monograph 19.

Walsh, R. J., Thomas, E. D., Chow, S. K., Fluharty, R. G., and Finch, C. A. (1949). Science, 110, 396. 